\title{
Staphylococcus aureus Nasal Colonization in Spanish Children. The COSACO Nationwide Surveillance Study
}

This article was published in the following Dove Press journal: Infection and Drug Resistance

Teresa del Rosal, ${ }^{1,2}$ Ana MéndezEchevarría, (D) ${ }^{1,2}$ Cesar Garcia-Vera, ${ }^{3}$ Luis Escosa-Garcia, ',2 Martin Agud,' Fernando Chaves, ${ }^{4}$ Federico Román, ${ }^{5}$ José Gutierrez-Fernandez, (iD ${ }^{6}$ Enrique Ruiz de Gopegui, ${ }^{7}$ Guillermo RuizCarrascoso, ${ }^{8}$ Maria del Carmen RuizGallego, ${ }^{9}$ Albert Bernet, ${ }^{10}$ Sara Maria Quevedo," 'Ana Maria FernándezVerdugo, ${ }^{12}$ Jesús Díez-Sebastian, ${ }^{13}$ Cristina Calvo (iD) ${ }^{1,2}$

On behalf of the COSACO Study Group

'Pediatric Infectious and Tropical Diseases Department, Hospital Universitario La Paz, Madrid, Spain; ${ }^{2}$ Translational Research Network in Pediatric Infectious Diseases (RITIP), Institute for Health Research IdiPAZ, Madrid, Spain; 3“José Ramón Muñoz Fernández" Health Care Center, Aragón Health Service, Zaragoza, Spain; ${ }^{4}$ Department of Clinical Microbiology, Hospital Universitario 12 de Octubre, Madrid, Spain; ${ }^{5}$ Laboratory of Nosocomial Infections,

Department of Bacteriology, CNM, Instituto de Salud Carlos III, Madrid, Spain; ${ }^{6}$ Department of Microbiology, Hospital Virgen de las Nieves, Granada, Spain; ${ }^{7}$ Department of Clinical Microbiology, Hospital Universitari Son Espases. Servicio de Microbiología, Palma de Mallorca, Spain; ${ }^{8}$ Department of Clinical Microbiology, Hospital Universitario La Paz, Madrid, Spain;

${ }^{9}$ Department of Microbiology, Hospital Universitario Virgen del Rocío, Sevilla, Spain; ${ }^{10}$ Section of Microbiology, Arnau de Vilanova University Hospital, Lleida, Spain; ' 'Department of Microbiology, Hospital Universitario Severo Ochoa, Leganes, Spain; ${ }^{12}$ Department of Microbiology, Hospital Universitario Central de Asturias, Oviedo, Spain; ${ }^{13}$ Department of Preventive Medicine, Hospital Universitario La Paz, Madrid, Spain

Correspondence: Ana Méndez-Echevarría Pediatric Infectious and Tropical Diseases Department. Hospital La Paz-IdiPAZ, Paseo de la Castellana 26I, Madrid 28046, Spain Tel/Fax +34-917277479

Email amendezes@yahoo.es
Objective: To assess the prevalence and risk factors for $S$. aureus and methicillin-resistant $S$. aureus (MRSA) nasal colonization in Spanish children.

Methods: Cross-sectional study of patients $<14$ years from primary care centers all over Spain. Clinical data and nasal aspirates were collected from March to July 2018.

Results: A total of 1876 patients were enrolled. Prevalence of S. aureus and MRSA colonization were 33\% (95\% CI 30.9-35.1) and 1.44\% (95\% CI 0.9-2), respectively. Thirtythree percent of the children $(633 / 1876)$ presented chronic conditions, mainly atopic dermatitis, asthma and/or allergy (524/633). Factors associated with $S$. aureus colonization were age $\geq 5$ years (OR 1.10, 95\% CI 1.07-1.12), male sex (OR 1.43, 95\% CI 1.17-1.76), urban setting (OR 1.46, 95\% CI 1.08-1.97) and the presence of asthma, atopic dermatitis or allergies (OR 1.25; 95\% CI: 1.093-1.43). Rural residence was the only factor associated with MRSA colonization (OR 3.62, 95\% CI 1.57-8.36). MRSA was more frequently resistant than methicillin-susceptible $S$. aureus to ciprofloxacin $[41.2 \%$ vs $2.6 \%$; $\mathrm{p}<0.0001$ ], clindamycin [26\% vs $16.9 \% ; \mathrm{p}=0.39$ ], and mupirocin [ $14.3 \%$ vs $6.7 \%$; $\mathrm{p}=0.18$ ] None of the MRSA strains was resistant to tetracycline, fosfomycin, vancomycin or daptomycin.

Conclusions: The main risk factors for $S$. aureus colonization in Spanish children are being above five years of age, male gender, atopic dermatitis, asthma or allergy, and residence in urban areas. MRSA colonization is low, but higher than in other European countries and is associated with rural settings.

Keywords: S. aureus, MRSA, child, colonization

\section{Introduction}

Staphylococcus aureus is the leading cause of skin and soft tissue infections (SSTIs) in children, ${ }^{1}$ and may cause bacteremia and other invasive diseases such as osteoarticular infections and pneumonia. ${ }^{2}$

For the past 20 years, an increase in both community-associated and hospitalacquired infections by $S$. aureus has been observed, ${ }^{3,4}$ causing significant morbidity and mortality. Methicillin-resistant $S$. aureus (MRSA) was first isolated in hospitalized and chronically ill patients. In the mid-1990s, community-associated cases started to emerge leading to changes in empirical treatments in areas where methicillin resistance exceeded $10 \%-15 \%$.

The rate of MRSA among community-acquired S. aureus (CA-MRSA) infection in children differs between countries. In Argentina, MRSA causes up to $65 \%$ of 
S. aureus community-acquired bacteremia in children. ${ }^{5}$ In the US, Sutter et al have reported a $31.6 \%$ prevalence of MRSA in community-onset $S$. aureus infections in $2014 .{ }^{6}$ In Greece, CA-MRSA has been identified in $35 \%$ of children admitted due to $S$. aureus osteoarticular infection, and in $75 \%$ of children with $S$. aureus pneumonia. ${ }^{3,7}$ The first case of CA-MRSA in a child in Spain was reported in $2006,{ }^{8}$ although current data regarding CA-MRSA infections in children in our country are scarce.

$S$. aureus colonization is associated with an increased risk of infection and contributes to transmission. Besides, it might be an important reservoir of resistance. A multicenter study performed in nine European countries reported a global prevalence of $21.6 \%$ of nasopharyngeal colonization by $S$. aureus. In this study, the prevalence of colonization in Spanish children was $31.5 \%$, but the percentage of MRSA was not specified. ${ }^{9}$

In settings with high CA-MRSA prevalence, empirical treatment of infections likely caused by $S$. aureus should address this potential threat. ${ }^{10}$ For all these reasons, we designed this study in order to estimate the prevalence of MRSA colonization in Spanish children who attend primary health-care centers for routine health screenings, as well as the risk factors associated with CA-MRSA nasal carriage. This will help to establish a proper empirical therapeutic approach in children with suspected community-acquired $S$. aureus infections.

\section{Methods}

We conducted a nationwide observational, cross-sectional multicenter study in children from community settings all over Spain (the COSACO study -Colonization by $S$. aureus in the Community). All research was performed in accordance with local regulations. Informed consent in accordance with the Declaration of Helsinki was obtained from the parents or guardians of all children before their inclusion, as well as from those patients aged 12 years or older. The study was approved by the Clinical Research Ethics Committee at La Paz University Hospital (Madrid) (PI18/00372).

\section{Study Participants}

Between March and July 2018, children under 14 years of age attending primary care for routine preventive assessments were recruited. Children presenting with an active infection during the visit (either confirmed or suspected) were excluded from the study. Seventy primary care centers from all the Spanish regions took part in the study.
According to region features and population density, at least two health-care centers (from rural, urban and mixed areas) were selected to take part in the study. The number of included patients was proportional to the pediatric population living in that region.

Primary care pediatricians from a pre-existing research network (PAPenRED) recruited patients in accordance with the study protocol, which included a homogeneous age distribution. Children were included every Tuesday and Thursday until recruitment was completed. Sample size was calculated for a $95 \%$ confidence level and a $3 \%$ margin of error, assuming a prevalence of nasal colonization of $20 \%$ for S. aureus and of $3 \%$ for MRSA. According to these data and taking into account a $15 \%$ of possible losses during the inclusion process, a minimum target of 1745 samples was established.

A survey was performed for each patient to collect clinical and epidemiological data including age; gender; siblings; household members; habitat type; child's and parents' origin; school/day-care attendance; exposure to livestock or pets; underlying chronic conditions; hospital admissions; antibiotic treatment in the previous month; and/or previous skin infections affecting the child or any of the household members.

\section{Study Samples}

Nasal swabs from every patient were collected following a standardized protocol, inserting the swab tip into the two nostrils and rotating it for five seconds in each one. ESwab $^{\mathrm{TM}}$ flocked swabs with Liquid Amies Medium (Copan, Brescia, Italy) were used. Nasal samples were submitted from each primary care center to its microbiology laboratory of reference belonging to hospitals of the National Health Service in Spain. Isolation and identification of $S$. aureus were based on standard microbiological procedures. For methicillin resistance screening, disk diffusion method with cefoxitin $(30 \mu \mathrm{g})$ was used. Susceptibility testing to other antibiotics was performed by microdilution or disk diffusion. Methods and antimicrobial susceptibility interpretations were in accordance with the EUCAST guidelines. ${ }^{11}$

\section{Statistical Analysis}

Values are expressed as percentages for discrete variables or as the mean and standard deviation for continuous variables. Categorical variables were compared using $\chi^{2}$ and Fisher's exact test, and continuous variables with Student's $t$ test or non-parametric tests, as appropriate. 
Logistic regression for multivariate analysis was performed according to the distribution and characteristics of the variables. A two-sided value of $p \leq 0.05$ was considered statistically significant. Odds ratio (OR) was used as measures of association, with $95 \%$ confidence interval (CI) to assess its precision. All analyses were performed using the Statistical Package for the Social Sciences, version 21.0 (IBM, Armonk, NY).

\section{Results}

We included 1876 children and their corresponding samples. The epidemiological and clinical characteristics of the cohort are shown in Table 1. A total of 619 samples were positive, meaning that $33 \%$ of children $(95 \%$ CI: 30.9-35.1) were colonized by $S$. aureus. MRSA was isolated in 27/619 positive samples (4.4\%; 95\% CI: $2.7-6.0)$. This implies an MRSA colonization prevalence of $1.4 \%$ in Spanish children (95\% CI: 0.9-2.0).

The comparison of the epidemiological features of colonized and non-colonized children is shown in Table 2. In the univariate analysis, children colonized by $S$. aureus were: older than 5 years of age; males; living in urban settings; attending school or daycare and having previous skin infections or underlying chronic conditions more frequently than non-colonized patients. Logistic regression analysis indicated a significantly higher risk of colonization by $S$. aureus for children older than five years of age, males, living in urban settings and with chronic diseases (Table 2). Thirtythree percent of the children included in the study presented some type of chronic condition (633/1876), mostly atopic dermatitis, asthma and/or allergy (82.7\%; $524 / 633)$. The presence of asthma, atopic dermatitis or allergies increased the risk of $S$. aureus colonization (OR 1.25; 95\% CI: 1.093-1.43).

S. aureus colonization prevalence by age and sex is reported in Supplementary materials (https://www.dove press.com/get supplementary file.php?f=282880.pdf). In children older than 10 years, we observed the greatest difference in the colonization rate between males and females $[49.3 \%$ vs $31.7 \%$; OR 2.09 (95\% CI; 1.49 2.94)]. In our cohort, the number of household members and siblings, foreign origin of children or parents, livestock or pet exposure and antibiotic treatment in the previous month had no impact on the carrier status.

Regarding MRSA colonization, a significantly higher rate was observed among children living in rural environments (OR 3.49; 95\% CI: 1.46-8.37) (Supplementary materials
Table I Epidemiological and Clinical Characteristics of the Study Cohort $(n=1876)$

\begin{tabular}{|c|c|c|}
\hline & & n (\%) \\
\hline \multirow[t]{3}{*}{ Age group (years) } & $0-4$ & $65 I(34.7)$ \\
\hline & $5-9$ & $647(34.5)$ \\
\hline & $10-14$ & $578(30.8)$ \\
\hline \multicolumn{2}{|l|}{ Mean age in years $(S D)^{*}$} & $7.01(4.38)$ \\
\hline \multicolumn{2}{|l|}{ Female gender } & $946(50.4)$ \\
\hline \multirow[t]{2}{*}{ Child's origin } & Foreign & $77(4.1)$ \\
\hline & Spanish & 1799 (95.9) \\
\hline \multirow[t]{2}{*}{ Mother's origin } & Foreign & $387(20.6)$ \\
\hline & Spanish & 1489 (79.4) \\
\hline \multirow[t]{2}{*}{ Father's origin } & Foreign & 357 (19) \\
\hline & Spanish & $1519(81)$ \\
\hline \multirow[t]{5}{*}{ Number of siblings } & 0 & $517(27.5)$ \\
\hline & 1 & $1016(54.2)$ \\
\hline & 2 & $252(13.5)$ \\
\hline & 3 & $59(3.2)$ \\
\hline & $\geq 4$ & $32(1.7)$ \\
\hline \multicolumn{2}{|c|}{ Mean number of individuals per household (SD) } & $4.01(0.99)$ \\
\hline \multirow[t]{3}{*}{ Habitat type } & Rural & $296(15.8)$ \\
\hline & Urban & $1188(64.3)$ \\
\hline & Mixed & $392(20.9)$ \\
\hline \multicolumn{2}{|l|}{ Livestock exposure } & $192(10.2)$ \\
\hline \multicolumn{2}{|l|}{ Pets at home } & $867(46.2)$ \\
\hline \multicolumn{2}{|c|}{ School or daycare attendance } & $1539(82)$ \\
\hline \multicolumn{2}{|c|}{ Antibiotic treatment in the previous month } & $105(5.6)$ \\
\hline \multirow[t]{3}{*}{ Previous skin infection } & Yes & $361(19.2)$ \\
\hline & No & $1418(75.6)$ \\
\hline & Unknown & $97(5.2)$ \\
\hline \multirow{3}{*}{$\begin{array}{l}\text { Other household } \\
\text { members with previous } \\
\text { skin infections }\end{array}$} & Yes & $94(5)$ \\
\hline & No & $1720(9 \mid .6)$ \\
\hline & Unknown & $62(3.3)$ \\
\hline \multicolumn{2}{|c|}{ Hospital admission in the last year } & $97(5.2)$ \\
\hline \multirow[t]{3}{*}{$\begin{array}{l}\text { Underlying chronic } \\
\text { disease }\end{array}$} & $\begin{array}{l}\text { Atopic dermatitis (with } \\
\text { no other atopic } \\
\text { manifestations) }\end{array}$ & $316(16.8 \%)$ \\
\hline & Asthma and/or allergies & 208 (II.I\%) \\
\hline & Others & $109(5.8 \%)$ \\
\hline
\end{tabular}

Abbreviation: SD, standard deviation.

https://www.dovepress.com/get_supplementary_file.php?f= 282880.pdf). No other risk factors related to CA-MRSA colonization were found. Children aged $0-4$ years had a CAMRSA colonization rate of 7.4\% (9/122), whereas 5-9 years and 10-14 years had 3.4\% (9/263) and 3.8\% (9/234) 
Table 2 Variables Analyzed as Possible Risk Factors for S. aureus Colonization

\begin{tabular}{|c|c|c|c|}
\hline \multicolumn{2}{|l|}{ Total Population $(n=1876)$} & \multirow{2}{*}{$\begin{array}{l}\text { S. aureus Colonized (n=6 I 9) } \\
\text { n (\%) }(95 \% \text { CI) or Mean (SD) } \\
122(\mid 8.7)(|5.7-2| .7) \\
263(40.7)(36.9-44.4) \\
234(40.5)(36.5-44.5)\end{array}$} & \multirow{2}{*}{$\begin{array}{l}\text { Magnitude (Cl } 95 \%) \\
\text { OR 5-I } 4 \text { years: } 2.96(2.36-3.72) *\end{array}$} \\
\hline Age group (years) & $\begin{array}{l}0-4(n=651) \\
5-9(n=647) \\
10-14(n=578)\end{array}$ & & \\
\hline $\begin{array}{l}\text { Mean age } \\
\text { (years) }\end{array}$ & $\begin{array}{l}\text { Colonized } \\
\text { Not colonized }\end{array}$ & $\begin{array}{l}8.19(3.96) \\
6.44(4.50)\end{array}$ & MD: 1.75 (1.35-2.15)* \\
\hline Gender & $\begin{array}{l}\text { Male }(n=930) \\
\text { Female }(n=946)\end{array}$ & $\begin{array}{l}339(36.5)(33.4-39.5) \\
280(29.6)(26.7-32.1)\end{array}$ & OR male: 1.36 (1.12-1.66)* \\
\hline Child's origin & $\begin{array}{l}\text { Foreign }(n=77) \\
\text { Spanish }(n=1799)\end{array}$ & $\begin{array}{l}26(33.8)(23.2-44.3) \\
591(32.8)(30.8-35.1)\end{array}$ & OR: I.04 (0.64-I.68) \\
\hline Mother's origin & $\begin{array}{l}\text { Foreign }(n=387) \\
\text { Spanish }(n=1489)\end{array}$ & $\begin{array}{l}115(29.7)(25.2-34.3) \\
502(33.7)(31.4-36.2)\end{array}$ & OR: $0.83(0.65-1.05)$ \\
\hline Father's origin & $\begin{array}{l}\text { Foreign }(n=357) \\
\text { Spanish }(n=1519)\end{array}$ & $\begin{array}{l}123(34.5)(29.5-39.4) \\
494(32.5)(30.3-35.0)\end{array}$ & OR: $1.09(0.85-1.38)$ \\
\hline Number of siblings & $\begin{array}{l}\text { Colonized } \\
\text { Not colonized }\end{array}$ & $\begin{array}{l}2.00(0.98) \\
1.97(1.01)\end{array}$ & MD: $0.03(-0.07-0.13)$ \\
\hline People per household & $\begin{array}{l}\text { Colonized } \\
\text { Not colonized }\end{array}$ & $\begin{array}{l}4.03(0.95) \\
4.00(1.01)\end{array}$ & MD: $0.03(-0.06-0.12)$ \\
\hline Habitat & $\begin{array}{l}\text { Urban }(n=1580) \\
\text { Rural }(n=296)\end{array}$ & $\begin{array}{l}538(34)(31.7-36.4) \\
81(27.4)(22.3-32.4)\end{array}$ & OR urban: I.37 (I.03-I.8I)* \\
\hline Livestock exposure & $\begin{array}{l}\text { Yes }(n=192) \\
\text { No }(n=1679)\end{array}$ & $\begin{array}{l}66(34.4)(27.7-44.1) \\
553(32.9)(30.6-35.1)\end{array}$ & OR: I.07 (0.78-I.47) \\
\hline Pets at home & $\begin{array}{l}\text { Yes }(n=867) \\
\text { No }(n=1002)\end{array}$ & $\begin{array}{l}282(32.5)(29.4-35.6) \\
333(33.2)(30.3-36.2)\end{array}$ & OR: $0.97(0.80-1.18)$ \\
\hline School/daycare attendance & $\begin{array}{l}\text { Yes }(n=1539) \\
\text { No }(n=336)\end{array}$ & $\begin{array}{l}55 I(35.8)(33.4-38.2) \\
68(20.2)(16.0-24.5)\end{array}$ & OR $2.19(1.65-2.92) *$ \\
\hline Previous antibiotic treatment & $\begin{array}{l}\text { Yes }(n=105) \\
\text { No }(n=|76|)\end{array}$ & $\begin{array}{l}28(56.7)(18.2-35.1) \\
588(33.4)(3 \mid .2-35.6)\end{array}$ & OR no antibiotic: $1.38(0.88-2.15)$ \\
\hline Previous skin infection & $\begin{array}{l}\text { Yes }(n=361) \\
\text { No }(n=|4| 8)\end{array}$ & $\begin{array}{l}136(37.7)(32.8-42.8) \\
455(32,1)(29.7-34.6)\end{array}$ & OR: I.29 (I.0I-I.63)* \\
\hline Hospital admission last year & $\begin{array}{l}\text { Yes }(n=97) \\
\text { No }(n=1774)\end{array}$ & $\begin{array}{l}26(26.8)(18.0-35.6) \\
59 \mid(33.3)(3|.|-35.5)\end{array}$ & OR: $1.36(0.86-2.16)$ \\
\hline Underlying chronic disease & $\begin{array}{l}\text { Yes }(n=633) \\
\text { No }(n=1240)\end{array}$ & $\begin{array}{l}242(38.2)(34.7-42.3) \\
375(30.2)(27.7-32.8)\end{array}$ & OR: $1.44(1.18-1.76)^{*}$ \\
\hline \multicolumn{4}{|l|}{ MULTIVARIATE ANALYSIS } \\
\hline $\begin{array}{l}\text { Age } \\
\text { Male gender } \\
\text { Urban habitat } \\
\text { Underlying chronic disease }\end{array}$ & & & $\begin{array}{l}\text { OR: I.IO (I.07-I.I2)* } \\
\text { OR: I.43 (I.I7-I.76)* } \\
\text { OR: I.46 (I.08-1.97)* } \\
\text { OR: I.27 (I.02-I.57)* }\end{array}$ \\
\hline
\end{tabular}

Note: *Significant results are represented in bold letters.

Abbreviations: SD, standard deviation; $\mathrm{MD}$, mean difference; $\mathrm{OR}$, odds ratio; $\mathrm{Cl}$, confidence interval. 


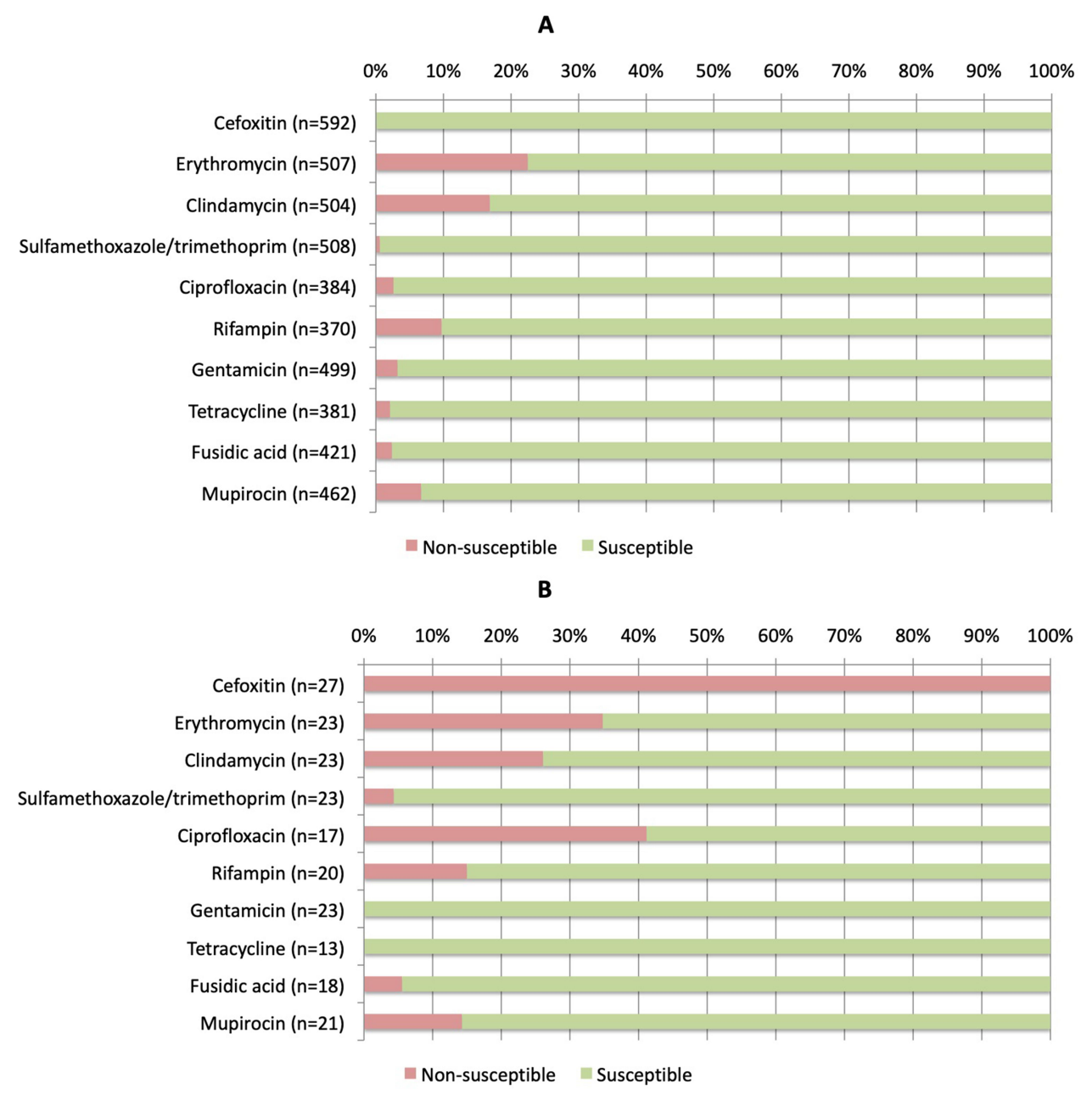

Figure I Antibiotic susceptibility results of methicillin-susceptible S. aureus (A) and methicillin-resistant strains (B).

respectively, although this trend was not statistically significant [OR 0-4 years vs 5-14: $2.12(0.93-8.45)]$.

Antibiotic susceptibility results are shown in Figure 1 and Supplementary materials (https://www.dovepress.com/ get supplementary file.php?f=282880.pdf). MRSA was more frequently resistant than methicillin-susceptible S. aureus (MSSA) to other antibiotics, including ciprofloxacin $[41 \%(7 / 17)$ vs $2.6 \%(10 / 384) ; \mathrm{p}<0.0001]$, erythromycin $[34 \% \quad(8 / 23) \quad$ vs $22 \% \quad(114 / 507) ; \quad p=0.17]$, clindamycin [26\% (6/23) vs $16.9 \%(85 / 504) ; \mathrm{p}=0.39]$, and mupirocin [14.3\% (3/21) vs $6.7 \%(31 / 462) ; \mathrm{p}=0.18]$. None of the MRSA strains associated resistance to tetracycline $(n=13)$, fosfomycin $(n=17)$, vancomycin $(n=21)$ or daptomycin $(n=20)$. Only one out of 18 strains was linezolid-resistant.

\section{Discussion}

This is the first study performed in Spain to determine the national prevalence and antibiotic resistance of commensal
S. aureus in children, and one of the largest in Europe analyzing more than 1,800 nasal swabs obtained in primary care centers. The prevalence of nasal carriage was higher than 30\% among Spanish children. The main risk factors for colonization were: age above 5 years; male gender; atopic dermatitis; asthma or allergy and residence in urban areas. MRSA prevalence was $1.4 \%$ and increased among children younger than 4 years and those living in rural areas.

Older children and young adults, as well as males, are known to be more frequently colonized by $S$. aureus. ${ }^{9,12-15}$ As we have observed, other authors have also reported higher colonization rates in urban settings in asymptomatic children or among adults with SSTIs. ${ }^{16,17}$ In our study, patients with chronic conditions presented higher rates of colonization, although most of them were atopic children. Patients with atopic dermatitis are mainly colonized by S. aureus, in contrast to children with healthy skin, who are more frequently colonized by $S$. epidermidis or 
S. hominis. ${ }^{18}$ It has been described in the past that earlylife skin colonization by $S$. aureus may contribute to the onset of atopic dermatitis. ${ }^{18} \mathrm{~S}$. aureus colonization has also been associated with asthma, food sensitization and allergy. ${ }^{19,20}$ As neither previous antibiotic treatments nor hospital admissions were associated with colonization, atopy itself seems to increase the risk for $S$. aureus colonization, and no other chronic conditions with frequent use of health-care services.

Higher colonization prevalence has also been reported among patients with SSTIs compared to controls. ${ }^{17}$ In our study, previous SSTI was a risk factor for colonization in univariate analysis but not in logistic regression analysis. Nevertheless, as patients with atopic dermatitis suffer more SSTIs than non-atopic children, ${ }^{18}$ it is likely that atopy is the real risk factor for colonization, as we have previously mentioned. Several authors have reported that children living in crowded settings or attending school are more likely to be colonized, ${ }^{15,21,22}$ as these settings increase human contact and the possibility of transmission. The contamination of inert surfaces and objects could have a major role in cross-transmission of pathogens in school settings, as with nosocomial infection acquisition. ${ }^{23}$ Some of the Staphylococcus strains have the ability to produce biofilms, which allow the bacteria to adhere to surfaces and foreign bodies. This is a virulence factor, which favors subsequent colonization and infection as previously reported. $^{24}$ Univariate analysis revealed that colonized children attended school or daycare more frequently than non-colonized ones, although this could not be proved by logistic regression analysis. Maternity leave lasted less than 20 weeks in our country, and following this period, many infants were admitted to day-care centers. ${ }^{25}$ Almost all children go to school at the age of three in our country $(96.5 \%){ }^{25}$ which could favor higher colonization rates.

Regarding CA-MRSA, multiple factors have been proposed that increase the risk of colonization, such as low socioeconomic status, living in crowded conditions, previous exposure to antibiotics and livestock exposure or pets. $^{26-30}$ In our cohort, we observed a higher percentage of MRSA carriage among children younger than 4 years of age.

Our observation is coincident with that reported by other authors, who have observed higher rates of CAMRSA infections in younger children, ${ }^{6,27}$ as higher colonization rates seem to increase the risk for subsequent infections. ${ }^{18}$ We did not find any other epidemiological factors that increased the risk of MRSA carriage, except for children living in rural areas, although the low number of MRSA strains isolated in our study could be a limitation for relevant conclusions.

None of the MRSA strains was associated with tetracycline resistance, a marker of livestock-associated MRSA. $^{31}$ In addition, no relationship was observed between the presence of pets in the household and MRSA colonization, suggesting that MRSA carriage is not a zoonotic problem among Spanish children.

In 2013, den Heijer et al reported the results of a large cross-sectional study (APRES study) ${ }^{9}$ performed by family doctors that compared the prevalence of nasal $S$ aureus carriage in patients (aged 4 years or older) across nine European countries, including Spain. More than 4,000 Spanish patients were included, but only $12 \%$ were younger than 20 years. The global prevalence of S. aureus nasopharyngeal colonization was $19 \%$ in our country, but it was higher in populations between 4 and 19 years of age $(31.5 \%)$. MRSA was isolated in $0.3 \%$ of the Spanish patients.

We have observed a slightly higher prevalence of $S$. aureus colonization in Spanish children, even with younger patients included in our study who usually have lower colonization rates, as we have previously described. Recent studies performed in different regions of Europe have also reported high $S$. aureus colonization rates in children $(34 \%$ to $53 \%){ }^{13,32}$ These data suggest that $S$. aureus colonization could be increasing in children in our continent. In addition, although the isolation of MRSA was low in our cohort (1.4\%), it is substantially higher than the rates reported by several authors in European children and even in adults $(0.14-0.8 \%)^{9,13,26,32}$ which is a concerning issue.

$S$. aureus carriage increases the risk of subsequent S. aureus infections, ${ }^{14,29,33}$ and most of the children who develop life-threatening $S$. aureus infections are young and previously healthy. ${ }^{6,27}$ Accordingly, the surveillance of $S$. aureus and MRSA colonization in children is important.

In the last decades, countries in the American continent and in the Asia-Pacific region have faced a dramatic increase of infections caused by CA-MRSA strains, ${ }^{27,29,34-36}$ which has led to changes in the initial empirical treatment upon $S$. aureus suspicion. ${ }^{35}$ In Europe, surveillance data show a general trend towards increasing MRSA infection from north to south, with higher prevalence in Spain, Italy and Greece. ${ }^{29}$ Several authors have reported high rates of MRSA in community-associated infections in children in southern Europe, with high ICU 
admission rates and longer hospitalizations. ${ }^{3,7}$ The different prevalence rates observed across Europe could be explained by different lifestyle conditions, infection control practices and antimicrobial use. ${ }^{9,15,26,29}$ Spain was the country with the highest rate of antibiotic use per habitant of all the countries included in the APRES study. It was also the one with the lowest percentage of pan-susceptible S. aureus strains. ${ }^{9}$ Our study found a higher resistance to clindamycin, ranging from $17 \%$ in MSSA to $26 \%$ in MRSA strains. Several authors have also reported a worrisome increase in clindamycin resistance in both MSSA and MRSA strains isolated from children with $S$. aureus infection in different countries. These rates were much higher than $15 \%,{ }^{6,7,37}$ exceeding $30 \%$ to $50 \%$ in some cases. ${ }^{6}$ We have additionally observed a high erythromycin resistance rate in our study, especially in MRSA strains, which can imply inducible clindamycin resistance. For all these reasons, when the local susceptibility rate drops below $85 \%$, clinicians should not use clindamycin in the empirical treatment of $S$. aureus infections, ${ }^{6}$ unless inhibition of toxin production is required. ${ }^{38}$

Rapid development of resistance to mupirocin has also been described over the last years. ${ }^{6,39,40}$ As intranasal mupirocin is the cornerstone for eradication therapy, the increasing rates of resistance are worrisome. ${ }^{40}$ Less than $1 \%$ of $S$. aureus strains from our study were resistant to sulfamethoxazole/trimethoprim, similarly to other European studies. ${ }^{9,38}$ This antibiotic can be a good alternative for nonsevere infections, as its efficacy is similar to clindamycin. ${ }^{41}$

Our study has some limitations. Samples were taken only from the anterior nares, leaving out other sites of colonization such as throat, groin, perineal region or rectum. Some authors have reported that oropharyngeal screening could increase the identification of $S$. aureus carriage by about $14 \%$, since some children are colonized exclusively in the throat. ${ }^{33}$ Previous studies have reported that staphylococcal strains colonizing the pharynx display more aggressive traits compared to those colonizing the anterior nares, which might have important implications on the risk of developing disease following colonization. ${ }^{42}$ Therefore, we could have underestimated the prevalence of $S$. aureus colonization in Spanish children. Secondly, we were not able to demonstrate a different rate of colonization in children of foreign origin, although the risk of CA-MRSA infection is higher in patients from Latin America and very low in Sub-Saharan Africa. ${ }^{43}$ As only
$4 \%$ of our patients were immigrants, a comparison between individual countries was not feasible.

The microbiological methods were not performed in a single reference laboratory, which could have contributed to homogenizing study results. However, we chose to carry out the microbiological studies in each primary care centers' reference laboratories to facilitate the organization and execution of the study. All the participating laboratories were accredited to carry out these microbiological procedures.

The 27 strains of MRSA detected in the study were not typified, which would have made it possible to confirm the community origin of the strains, or to suggest the possible hospital or livestock association. The epidemiology of MRSA is transforming into a blurry boundary between HA-MRSA and CA-MRSA due to a constant transfer of strains between the community and hospitals, as previously documented. ${ }^{44}$ Nevertheless, the main strength of this surveillance study is that it includes children of all ages, who live in rural and urban settings all over Spain. It provides important and reliable information regarding $S$. aureus carriage in the pediatric population, as well as updated and relevant antibiotic resistance data in a European Mediterranean country.

\section{Abbreviations}

CA, community-acquired; CI, confidence interval; MRSA, methicillin-resistant S. aureus; MSSA, methicillin-susceptible $S$. aureus; OR, odds ratio; SSTIs, soft tissue infections.

\section{Acknowledgments}

To Claire Marsden and Dr. Kinga Amália Sándor-Bajusz for the revision of the English language. To all the member of the COSACO STUDY GROUP, who have collaborated in the samples collection and processing and clinical data acquisition. (M.R. Albañil- Ballesteros, M. Alcaraz-Quiñonero, E. Alvarez-Bueno, J. Anillo-Lago, J.M. Azcona-Gutierrez, F. Baquero-Artigao, J. Blanco- Gonzalez, A. Bercedo-Sanz, J.V. Bernad-Usoz, M. Biosca- Pamies, A. Bonet-Garrosa, C. Borja-Perez, B. Botella-Serrano, M.A. CaballeroMorales, M. Carballal-Mariño, M.T. Calvo-Lorenzo, J.E. Callejas-Pozo, A. Caro-Gomez, I. Casares- Alonso, G. Castillo-Aguas, C. Cayuela, J.L. Díaz de Tuesta, J. DíezSebastian, B. Dominguez, M. Duelo-Marcos, Y. Escanciano, C. Esteban-Redondo, F.J. Fernandez- Lopez, M.I. Galán Navarro, A. Gallego-Iborra, F. García-García, A. García-Merino, R. García- Perez, M. Gasca-Santiyán, 
I. Gil-Alexandres, S. Giner-Almaraz, M. Giribet- Folch, M.

C. Gonzalez-Velasco, R. Gomez Casares, A. Gomez-Cobiá, D. Gros- Esteban, B. Guillot-Roselló, J.A. Heras-Galindo, A. B. Hidalgo- Calero, A. Iofrio De Arece, R. Jimenez Ales, J Jové-Naval, M.N Larrosa-Escartín, A. Leal-Negredo, C. Lobelle, I. López- Hernandez, A. Lorente García-Mauriño, M. Lozano-Vergara, S. Marfil-Olink, L. Martinez, M. Martinez, R.M. Masvidal, N. MenendezGonzalez, J. Mengual-Gil, R. Minguez-Verdejo, I. Miranda, C. Mourelo, M.E. Muñoz-Hiraldo, B. Nogueira-Gonzalez, V. Ortiz-Revuelta, M.A. Ordoñez- Alonso, P. Oscola, M.L. Padilla-Esteban, I. Perez-García, J. Pita-Carretero, D. Quílez -Agreda, R.M. Ramirez- Gavira, MJ. Ramos, E. Rico-Mari, M. Rodriguez, S. Rodriguez- Moldes, E. Rodriguez-Salinas, E. Ruiz-Chercoles, C.A Salas-Venero, T. Sainz, F. Sanatorio, E. Sanchez-Almeida, N. Sanchez-Cordero, M.D. SanchezDíaz, M. Sanchez-Echenique, B. Sancho-Madrid, C. Seral, C.I. Servera- Ginard, S. Solaz-Barrios, E. Suarez-Vincente, M.L. Torres-Alvarez de, C. Torres-Lloret, I. Ubeda-Sansano, M.J. Vaquerizo- Pollino, M.D. Villar- Fernandez, O. RubioRemiro, B. Viñado, A. Viudes de Velasco, A. Yagüe).

\section{Funding}

This study has been supported by The Spanish Ministry of Science and Innovation - Instituto de Salud Carlos III, and Fondos FEDER of the EU, Grant N ${ }^{\circ}$ PI18CIII/00372 [Fondo de Investigaciones Sanitarias-Spanish Health Research Fund (ISCIII)]; Grant Award "Jose María Corretger" from the Spanish Society for Pediatric Infectious Diseases; Grant Research Award from the Spanish Association of Pediatric Primary Care; and a Small Grant Award from the European Society for Pediatric Infectious Diseases.

\section{Disclosure}

The authors declare that they have no potential conflicts of interest.

\section{References}

1. Barrios Lopez M, Gomez Gonzalez C, Orellana MA, Chaves F, Rojo P. Staphylococcus aureus abscesses: methicillin-resistance or Panton-Valentine leukocidin presence? Arch Dis Child. 2013;98 (8):608-610. doi:10.1136/archdischild-2012-302695

2. Pai S, Enoch DA, Aliyu SH. Bacteremia in children: epidemiology, clinical diagnosis and antibiotic treatment. Expert Rev Anti Infect Ther. 2015; 13:1073-1088.

3. Bouras D, Doudoulakakis A, Tsolia M, et al. Staphylococcus aureus osteoarticular infections in children: an 8-year review of molecular microbiology, antibiotic resistance and clinical characteristics. $J$ Med Microbiol. 2018;67:1753-1760. doi:10.1099/jmm.0.000859
4. Daskalaki M, Rojo P, Marin-Ferrer M, Barrios M, Otero JR, Chaves F. Panton-Valentine leukocidin-positive Staphylococcus aureus skin and soft tissue infections among children in an emergency department in Madrid, Spain. Clin Microbiol Infect. 2010;16:74-77. doi:10.1111/j.1469-0691.2009.02830.x

5. Pérez G, Martiren S, Reijtman V, et al. Community-acquired Staphylococcus aureus bacteremia in children: a cohort study for 2010-2014. Arch Argent Pediatr. 2016;114:508-513.

6. Sutter DE, Milburn E, Chukwuma U, Dzialowy N, Maranich AM, Hospenthal DR. Changing Susceptibility of Staphylococcus aureus in a US Pediatric Population. Pediatrics. 2016;137(4):e20153099e20153099. doi:10.1542/peds.2015-3099

7. Doudoulakakis AG, Bouras D, Drougka E, et al. Communityassociated Staphylococcus aureus pneumonia among Greek children: epidemiology, molecular characteristics, treatment, and outcome. Eur J Clin Microbiol Infect Dis. 2016;35(7):1177-1185. doi:10.1007/ s10096-016-2651-7

8. Broseta A, Chaves F, Rojo P, Otero JR. Emergence of a single clone of community-associated methicillin-resistant Staphylococcus aureus in southern Madrid children. Enferm Infecc Microbiol Clin. 20 06;24:31-35. doi:10.1157/13083373

9. den Heijer CD, van Bijnen EM, Paget WJ, et al. Prevalence and resistance of commensal Staphylococcus aureus, including meticillin-resistant $\mathrm{S}$ aureus, in nine European countries: a cross-sectional study. Lancet Infect Dis. 2013;13:409-415. doi:10.1016/S1473-3099(13)70036-7

10. Chuck EA, Frazee BW, Lambert L, McCabe R. The benefit of empiric treatment for methicillin-resistant Staphylococcus aureus. J Emerg Med. 2010;38(5):567-571. doi:10.1016/j.jemermed.2007. 11.037

11. EUCAST. European committee on antimicrobial susceptibility testing breakpoint tables for interpretation of MICs and zone diameters. Eur Comm Antimicrob Susceptibility Testing. 2018.

12. Wertheim HFL, Melles DC, Vos MC, et al. The role of nasal carriage in Staphylococcus aureus infections. Lancet Infect Dis. 2005;5 (12):751-762. doi:10.1016/S1473-3099(05)70295-4

13. Laub K, Tóthpál A, Kovács E, et al. High prevalence of staphylococcus aureus nasal carriage among children in Szolnok, Hungary. Acta Microbiol Immunol Hung. 2018;65:59-72.

14. Erikstrup LT, Dinh KM, Andersen PS, et al. Cohort description: the Danish Blood Donor Staphylococcus aureus Carriage Study. Clin Epidemiol. 2019;11:885-900. doi:10.2147/CLEP.S218637

15. Rodríguez EA, Correa MM, Ospina S, Atehortúa SL, Jiménez JN. Differences in epidemiological and molecular characteristics of nasal colonization with Staphylococcus aureus (MSSA-MRSA) in children from a university hospital and day care centers. PLoS One. 2014. doi:10.1371/journal.pone. 0101417

16. Hanson BM, Kates AE, O'Malley SM, et al. Staphylococcus aureus in the nose and throat of Iowan families. Epidemiol Infect. 2018;146:1777-1784. doi:10.1017/S0950268818001644

17. Kumar N, David MZ, Boyle-Vavra S, Sieth J, Daum RS. High Staphylococcus aureus colonization prevalence among patients with skin and soft tissue infections and controls in an urban emergency department. J Clin Microbiol. 2015;53:810-815. doi:10.1128/JCM. 03221-14

18. Kim J, Kim BE, Ahn K, Leung DYM. Interactions between atopic dermatitis and Staphylococcus aureus infection: clinical implications. Allergy Asthma Immunol Res. 2019;11:593. doi:10.4168/aair.2019.11. 5.593

19. Kim Y-C, Won H-K, Lee JW, et al. Staphylococcus aureus nasal colonization and asthma in adults: systematic review and meta-analysis. J Allergy Clin Immunol Pract. 2019;7(606-15.e9).

20. Tsilochristou O, du Toit G, Sayre PHet al. Association of Staphylococcus aureus colonization with food allergy occurs independently of eczema severity. $J$ Allergy Clin Immunol. 2019;144:494-503. doi:10.1016/j.jaci.2019.04.025 
21. Lin J, Peng Y, Xu P, et al. Methicillin-resistant Staphylococcus aureus nasal colonization in Chinese children: a prevalence meta-analysis and review of influencing factors. PLoS One. 2016;11(7):e0159728. doi:10.1371/journal.pone.0159728

22. Knox J, Uhlemann AC, Lowy FD. Staphylococcus aureus infections: transmission within households and the community. Trends Microbiol. 2015;23:437-444. doi:10.1016/j.tim.2015.03.007

23. Russotto V, Cortegiani A, Fasciana T, et al. What healthcare workers should know about environmental bacterial contamination in the intensive care unit. Biomed Res Int. 2017;2017:1-7. doi:10.1155/ 2017/6905450

24. Calà C, Amodio E, Di Carlo E, Virruso R, Fasciana T, Giammanco A. Biofilm production in Staphylococcus epidermidis strains, isolated from the skin of hospitalized patients: genetic and phenotypic characteristics. New Microbiol. 2015;38:521-529.

25. Spanish Statistic Institute. Net enrollment rates in early childhood education by age in Spain, 2017. Available from: https:/www.ine.es/ jaxiT3/Datos.htm?t=13228\#!tabs-tabla. Accessed November 3, 2020.

26. Tavares DA, Sá-Leão R, Miragaia M, de Lencastre H. Large screening of CA-MRSA among Staphylococcus aureus colonizing healthy young children living in two areas (urban and rural) of Portugal. BMC Infect Dis. 2010;10. doi:10.1186/1471-2334-10-110

27. Immergluck LC, Leong T, Matthews K, et al. Geographic surveillance of community associated MRSA infections in children using electronic health record data. BMC Infect Dis. 2019:19. doi:10.1186/ s12879-019-3682-3.

28. Neves FPG, Marlow MA, Rezende-Pereira G, et al. Differences in gram-positive bacterial colonization and antimicrobial resistance among children in a high income inequality setting. BMC Infect Dis. 2019:19. doi:10.1186/s12879-019-4104-2.

29. Lee AS, de Lencastre H, Garau J, et al. Methicillin-resistant Staphylococcus aureus. Nat Rev Dis Prim. 2018;4:18033. doi:10.1038/nrdp.2018.33

30. Hogan PG, Mork RL, Boyle MG, et al. Interplay of personal, pet, and environmental colonization in households affected by community-associated methicillin-resistant Staphylococcus aureus. J Infect. 2019;78:200-207.

31. Ceballos S, Aspiroz C, Ruiz-Ripa L, et al. Epidemiology of MRSA CC398 in hospitals located in Spanish regions with different pig-farming densities: a multicentre study. J Antimicrob Chemother. 2019;74:2157-2161. doi:10.1093/jac/dkz180

32. Esposito S, Terranova L, Zampiero A, et al. Oropharyngeal and nasal carriage by healthy children. BMC Infect Dis. 2014;14:1. doi:10.1186/s12879-014-0723-9

33. Nelson RE, Evans ME, Simbartl L, et al. Methicillin-resistant Staphylococcus aureus colonization and pre- and post-hospital discharge infection risk. Clin Infect Dis. 2019;68:545-553. doi:10.1093/ cid/ciy507
34. Valderrama-Beltrán S, Gualtero S, Álvarez-Moreno C, et al. Risk factors associated with methicillin-resistant Staphylococcus aureus skin and soft tissue infections in hospitalized patients in Colombia. Int J Infect Dis. 2019;87:60-66. doi:10.1016/j.ijid.2019.07.007

35. Penteado FD, Tubero TZ, Hein N, Gilio AE. Frequency of community-acquired methicillin-resistant staphylococcus aureus in pediatric population in a General Hospital in São Paulo, Brazil, Over 5 Years. Pediatr Infect Dis J. 2019;38:e87-e89. doi:10.1097/INF.0000000 000002158

36. Roediger JC, Shadbolt B, Philip N, Britton ACO. Paediatric Staphylococcus aureus bacteraemia: a single-centre retrospective cohort. J Paediatr Child Health. 2017;53(180-6).

37. Gordon O, Cohen MJ, Gross I, et al. Staphylococcus aureus Bacteremia in children: antibiotic resistance and mortality. Pediatr Infect Dis J. 2019;38:459-463. doi:10.1097/INF.0000000000002202

38. Gijón M, Bellusci M, Petraitiene B. et al. Factors associated with severity in invasive community-acquired Staphylococcus aureus infections in children: a prospective European multicentre study. Clin Microbiol Infect. 2016;22:643.e1-643.e6. doi:10.1016/j.cmi.2016.04.004

39. Acree ME, Morgan E, David MZ. S. aureus infections in Chicago, 2006-2014: increase in CA MSSA and decrease in MRSA Incidence. Infect Control Hosp Epidemiol. 2017;38:1226-1234. doi:10.1017/ ice. 2017.177

40. Antonov NK, Garzon MC, Morel KD, Whittier S, Planet PJ, Lauren CT. High prevalence of mupirocin resistance in Staphylococcus aureus isolates from a pediatric population. Antimicrob Agents Chemother. 2015;59:3350-3356. doi:10.1128/AAC.00079-15

41. Miller LG, Daum RS, Buddy Creech C, et al. Clindamycin versus trimethoprim-sulfamethoxazole for uncomplicated skin infections. N Engl J Med. 2015;372:1093-1103. doi:10.1056/NEJMoa1403789

42. Săndulescu O, Bleotu C, Matei L, et al. Comparative evaluation of aggressiveness traits in staphylococcal strains from severe infections versus nasopharyngeal carriage. Microb Pathog. 2017;102:45-53. doi:10.1016/j.micpath.2016.11.006

43. Nurjadi D, Fleck R, Lindner A, et al. Import of communityassociated, methicillin-resistant Staphylococcus aureus to Europe through skin and soft-tissue infection in intercontinental travellers, 2011-2016. Clin Microbiol Infect. 2019;25:739-746. doi:10.1016/j. cmi.2018.09.023

44. Mammina C, Calà C, Bonura C, et al. Polyclonal non multiresistant methicillin resistant Staphylococcus aureus isolates from clinical cases of infection occurring in Palermo, Italy, during a one-year surveillance period. Ann Clin Microbiol Antimicrob. 2012;11(1):17. doi:10.1186/1476-0711-11-17
Infection and Drug Resistance

\section{Publish your work in this journal}

Infection and Drug Resistance is an international, peer-reviewed openaccess journal that focuses on the optimal treatment of infection (bacterial, fungal and viral) and the development and institution of preventive strategies to minimize the development and spread of resistance. The journal is specifically concerned with the epidemiology of antibiotic resistance and the mechanisms of resistance development and diffusion in both hospitals and the community. The manuscript management system is completely online and includes a very quick and fair peerreview system, which is all easy to use. Visit http://www.dovepress.com/ testimonials.php to read real quotes from published authors. 